\title{
SOME THOUGHTS ON THE RELATIONS BETWEEN ANIMAL AND HUMAN DRUG-TAKTNG
}

\author{
JAMES H. WOODS \\ Departments of Pharmacology and Psychology \\ University of Michigan \\ Ann Arbor, Michigan
}

(Final form, November 1983)

\section{Contents}

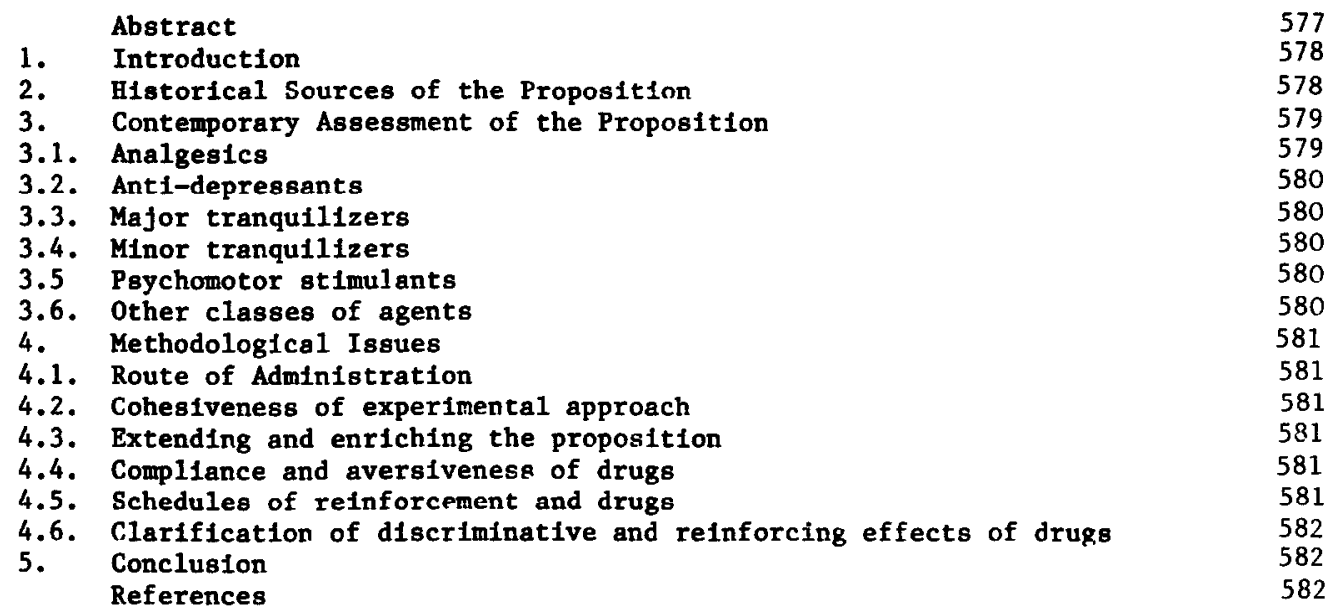

\section{Abstract}

Woods, J.H.: Some thoughts on the relation hetween animal and human irug-taking. Prog. Neuro-Psychopharmacol. \& Biol. Psychiat. 7(4-6):577-584.

1. Results of studies of drug self-administration have frequently been suggested as Indicators of the potential for abuse of these drugs by humans. Historical data (pre 1970), although scant, supported this suggestion for drugs such as morphine and ethanol that served as reinforcers in both human and non-human experimental subjects. More recent information indicated that, whlle the correlation between human and non-human drug, self-administistration may be high, there are apparently, occasional exceptions. In the narcotic analysis and antidepressant classes of pharmacological compounds, there are drugs that maintain high response rates in animals, but have not yet been shown to result in significant abuse problems in man. Various methodological issues, related to the general proposition and the exceptions to tt are discussed.

Reywords: animals, drug self-administration, human reinforcing effects 


\section{Introduction}

My contribution to this drug self-administration symposium (held at the 6 th Annual meeting of the Canadian College of Neuropsychopharmacology) is an evaluation of the proposition that drugs that are self-administered by experimental animals are drugs that are abused by humans. In other words, the determination that a drug is seif-administered by experimental animals is predictive of its abuse liability in humans. This is a very general, seemingly simple, proposition. It has developed from the increasing body of information on drug selfadministration in animals and the rather meagre information, but sizable opinion, on human drug abuse. How useful a proposition is it? Does the proposition hold both within and across classes of drugs subject to abuse? Are there limits to our knowledge, procedures, findings, or concepts that suggest directions for future research to test the proposition more thoroughly?

The validity of the proposition could hinge on the procedural and conceptual definitions of human drug abuse and drug use and as well, on our conceptual skil1 and experienced knowledge in making distinctions in the grey area between abuse and use. However, since we need to obviate, if not eliminate, the moralistic overtones inherent in making this distinction, we will place our focus on the most objective and direct measures of the human drug-taking behavior available. Thus, we will skirt the difficult conceptual issue of a general definttion of human drug abuse and instead simply describe examples of experimental human drug-taking. The more similar these examples are procedurally to examples of drug-taking in animals, the easier it will be to use these examples to test the proposition. A working definttion of drug taking in animals is behavior that is relnforced by the delivery of a drug. Usually, the behavior is a simple response. The frequency of this response will increase relative to its frequency in a period prior to the introduction of drug delivery, if drug delivery is contingent on the response, and that particular drug serves as a reinforcer.

\section{Historical sources of the proposition}

The rich anecdotal history of human drug taking provided a rough chart for early research on drug-taking in animals. The prime concerns appeared, with appropriate ethnocentrism, to be narcotic and alcohol selfadministration in animals. Much experimental work in animals was devoted to alcohol (see Lester [1966] for an interesting review of the early research), but little of it appeared relevant to the human condition of alcoholism; animals didn't consume enough ethanol to show significant signs of acute intoxication nor did withdrawal signs develop following chronic exposure to ethanol. With narcotics, a number of early experiments were done with rodents and a single experiment with chimpanzees. However, it was not unti1 a study by Weeks (1962) that a feasible technique was demonstrated for studying the reinforcing effect of a narcotic using operant conditioning principles. Weeks showed that rats made dependent on morphine by passive infusion would readily make a lever-press response that resulted in the intravenous delivery of morphine. In addition, he showed that both behavioral and pharmacological manipulations in these rats led to large changes in self-administration behavior. Thus, morphine-reinforced responding was increased by reducing the dose of morphine delivered (changing reinforcer magnitude), by administration of nalorphine (producing acute withdrawal), and changing the number of the responses required for morphine delivery (changing response probability and reinforcement interval). Another very important paper (Thompson and Schuster, 1964) established similar findings with morphine in rhesus monkeys. These studies pointed to the viability of the application of operant conditioning techniques and theory to problems of drug dependence, and paved the way for later studies that were relevant in testing the proposition we are examining.

Deneau, Yanagita and Seevers (1969) showed that rhesus monkeys 1mplanted with chronic intravenous catheters would self-administer a variety of drugs known to be abused by man. They found morphine, codeine, cocaine, d-amphetamine, pentobarbital, and ethanol to reinforce a behavioral response in the monkey. A number of other compounds were not self-administered at levels greater than those produced by saline. These were nalorphine, morphine-nalorphine mixtures, chlorpromazine, caffeine, and mescaline. Deneau and Inoki (1967) found intravenous nicotine to maintain modest rates of responding though not 
clearly above those maintained by the vehicle. Hoffmeister and Goldberg (1973) found, in a situation in which morphine and d-amphetamine were readily self-admintstered, neither chlorpromazine nor tmipramine maintained self-injection responding in rhesus monkeys. Thus, a varlety of drugs that are differentiated therapeuticaliy and on the basis of their central mechanisms of actions functioned quite differently as reinforcers in primates. It was also of considerable importance that the amounts of compound self-administered led to some forms of severe, acute behavforal effects (e.g., stereotypy with amphetamine) or chronic effect (e.g., withdrawal signs with alcohol). These effects led some of these Investigators to argue that only under these conditions would important aspects of human drug addiction be captured (Deneau et al., 1969).

Much of what was known of human self-administration of drugs was established by simple narrative or less formal epidemiological studies of drug use and abuse. This information suggested that many narcotic analgesics, stimulants, and hypnotic agents were subject to abuse in humans, while antipsychotic drugs and antidepressant drugs, in general, were not. To knowledge, the first experimental study of human drug self-administration was carried out by Wikler (1952) who followed a single subject self-administering morphine over a six-month period. The pattern of drug consumption was quite similar to that of the rhesus monkey in the studies described above. Mello and Mendelson (1965) were the f1rst investigators to use operant techniques with human alcohol users. They analyzed alcohol consumption by alcoholics and found high response rates when beverage alcohol was made contingent on the response. These reports were the first to show that humans could serve as experimental subjects in studies of drug selfadministration. The study by Mello and Mendelson was also important in demonstrating that operant conditioning procedures could be applied to human subjects to evaluate the reinforcing effects of drugs. Thus, the feasibility of making fairly close comparisons between animal and human experimental drug-taking was made excitingly clear.

The common thread to our proposition, applied to both human and animal experiments, is clearly the concept of the drug as a reinforcer. This theme continues as the central focus of the next section of the review. This brief and selected view of the history of the proposition establishes clearly that many of the prototypic agents that have been abused by man are self-administered by primates. Likewise, the negative cases of chlorpromazine, nalorphine, and imipramine Jent important further evidence to the proposition.

\section{Contemporary assessment of the proposition}

Fairly extensive sets of self-administration studies allow interesting generalizations about many classes of centrally acting agents.

3.1. Analgesics. Many morphine-like analgesics are self-injected by primates (e.g., Woods et al., 1982; Young et al., in press). V1rtually all morphine-1ike drugs that have raptd onsets of action function as reinforcers. Indeed, of 16 compounds from each of the major chemical families of opioids examined in rhesus monkeys, all maintained self-injection responding. There was a strong positive correlation between the potency of a compound in malntaining drug-reinforced responding and the potency of the compound in suppressing the morphine withdrawal syndrome (Young et al., 1981). When exceptions to this correlation were found (e.g., Winger et al., 1983), a slow onset of action was the 1ikely explanation.

Narcotic analgesics that have actions at different receptors (kappa rather than mu) and different profiles of behavorial action are not self-injected at rates comparable to those maintained by codeine or morphine even though they have quite rapid onsets of action (e.g., Woods et al., 1979, 1982). None of these kappa compounds has been marketed as yet; some (e.g., nalorphine and cyclazocine) have produced atrong dysphoric effects in humans. These agents have also been shown to be aversive in primates (Hoffmelster and Wuttke, 1973).

Nelther acetylsalicyclic acid, phenylbutazone, phenacetin nor some analogues of these agents were self-infected by monkeys (Hoffmeister, 1979). Zomiperac also falled to malntain significance self-injection responding in the monkey (Woods et al., 1983b). Thus, 
significant analgesia through non-oplate mechanisms may be obtained with these compounds without the production of reinforcing effects.

It has been found that nalbuphine and butorphanol maintain high rates of responding when their intravenous delivery is contingent on an operant response in the monkey (Young et al., In press). Yet both of these drugs have been avallable as analgesics in the United States for some time, and no significant abuse of them has been reported. While this may Indicate that our proposition is flawed, it may also mean that the use of these drugs is restricted to a population unlikely to abuse them. A comparison of the abuse liability of these compounds relative to morphine in patients who have received these drugs for pain relief would help to clarify this question.

3.2. Anti-depressants. The reinforcing effects of these agents has not been studied as thoroughly as those of many other classes of agents. Hoffmelster (1977) reported that neither intravenous imipramine nor amitryptyline functioned as either positive or negative reinforcers in the monkey. Nomifensine (Woods, 1978) was reported to maintain significant self-infection responding in the monkey, yet there are no reported cases of human abuse, though the compound has been marketed in Europe for a considerable pertod. Bupropion also maintains significant self-injection responding in monkeys (Woods et al., 1983a). Yet, preclintcal evaluation in humans suggests no characteristics in common with amphetemine as least by the oral route of administration (Griffith et al., 1983). These apparent contradictions to the proposition mean that there may be important species, route of administration, and/or procedural differences that need to be examined in greater detall.

3.3. Major tranquilizers. All major tranquilizers that have been studied to date have failed to maintain significant self-injection responding in primates; Indeed, some maintain responding that prevents their injection (e.g. Hoffmeister, 1977). It would be extremely interesting both theroretically and from the point of therapeutic trial to discover a major tranquilizer that would malntain self-injection responding.

3.4. Minor tranquilizers. Many of the benzodiazepine ninor tranquilizers that have been studied to date maintain only modest rates of intravenous drug self-injection in primates with the exception of the very short acting compounds midazolam and triazolam (Yanagita, 1981; Woods, 1982; Lukas and Griffiths, 1982). A few formal experiments on drug preference suggest that diazepam fails to reinforce responding in normal (Johanson and Uhlenhuth, 1980) or anxious subjects (dewtt et a1.,1983). In sedative abusers, when compared to pentobarbital, diazepam is not preferred even at doses at which comparable subjective effects are obtained (Griffiths et al., 1980). Unfortunately, only a very few benzodiazepines have been studied in this way in different human subject populations.

3.5. Psychomotor stimulants. Many agents of the cocaine-amphetamine type maintain self-injection responding (e.g., Wilson et al., 1971; Griffiths et al., 1976). Slight structural modifications, however, lead to significant alterations in reinforcing potency and efflcacy (Tessel and Woods, 1978) producing some compounds that apparently suppress appet1te without having reinforcing effects, e.g., fenfluramine (Woods and Tessel, 1974 ). This difference in reinforcing effect between fenfluramine and amphetamine, however, may lead to a negative effect upon compliance when these drugs are used in weight control programs (B1gelow et al., 1980).

3.6. Other classes of agents. Many of the drugs that share actions with phencyclidine act as reinforcers (e.g. Balster et al., 1973; Young and Woods, 1981); these drugs have not been studied formally though abuse of phencyclidine is prevalent in certain countries particularly the United States. Certain antihistamines (e.g., tripelennamine [Krohn et al., 1982]) and local anesthetics (e.g., procaine [Ford and Balster, 1977]) act as reinforcers though abuse of them by themselves has been noted very infrequently. There 1s, however, abuse of pentazocinetripelennamine combinations in the United States and Canada.

In summary, some important qualifications need to be considered for the proposition. There are drugs that are self-administered by animals for which there is little evidence of abuse in humans. These exceptions and their congeners need to be studied more thoroughly in different populations of human subjects. Ilkewlse, there are drugs abused by humans that fail to malntaln self-injection responding in animals, e.g., 
tetrahydrocannabinol (Carney et al., 1977) and the hallucinogens, LSD and mescaline (Deneau et al., 1969). These compounds, to the extent that it is ethically feasible, should slso be studied more formally using operant procedures in humans. In addition, other behavorial procedures (see below) should be studied in animals. It may be that changes in procedure would allow a reinforcing effect of these drugs to be evidenced in animals, a finding that would help ldentify factors that might limit or extend the reinforcing effects of these drugs.

\section{Methodological issues}

4.1. Route of Administration. While the reinforcing effects of drugs in animals is usualiy evaluated by the Intraveneous route, many drugs are taken by humans by other routes of administration than the intravenous route. Route of administration may effect the reinforcing effects of some drugs. Considerable progress has been made in animal studies using orally delivered drugs as reinforcers (e.g. Meisch and Carro11, 1981) allowing more direct comparison to human drug-taking. Intramuscular injections (Goldberg and Gardner, 1981) and Intragastric injections (Yanagita, 1981) have also been used successfully and may also provide appropriate experimental comparisons across species. Finally, inhalation procedures have been used with nitrous oxide (Wood et a1., 1977) and other agents (Yanagita et $\mathrm{A1.,}$ 1970) providing st111 other opportunities for comparison in human studies and allowing intraspecies comparisons of route of administration on the reinforcing effects of drugs.

4.2. Cohesiveness of experimental approach. It would be 1deal to isolate and study each of the procedural differences across studies of the reinforcing effects of drugs in animals and humans. All concerned would be advised to carry out experiments with the hope in mind that some facet of the research could be replicated in other research using other species. often too little regard is given this particular issue. Enormous strides have been made over the last 20 years; one can look forward to increasing amounts of procedural similarity so that more understanding will be gained of studies both in animals and humans. As we gain greater experimental control over drugs as reinforcers one can expect to rely less upon the narrative and anecdotal reports of human drug abuse except as a guide for supplementing and expanding the information base.

\subsection{Extending and enriching the proposition}

As noted above, the general proposition may be enriched by studing the exceptions to the proposition in enough detail to understand why they exist. In addition, much needs to be extended especially in the area of human behavioral pharmacology of drug-taking. In addition, there are some areas of interest that may have general applicability to the study of drugs as reinforcers.

4.4. Compliance and averstveness of drugs. The aversive properties of drugs have not been nearly as well studied as the positive reinforcing porperties of drugs, desplte the fact that the techniques used are nearly identical. Issues of the aversive porperties of drugs in experimental animals and humans are just as relevant to our proposition as are data on the rate-maintaining effects of drugs. Demonstration of the aversiveness of drugs in animals could predict possible compliance problems in the human population. Likewise these types of studies in humans could be carried out in a variety of therapeutic contexts in which compliance has been a major problem, e.g., cancer chemotherapy and antihypertensive medication.

4.5. Schedules of reinforcement and drugs. The reinforcing effect of a drug is dependent upon the schedule of its delivery; the identification of reinforcing effects of some drugs (e.g., nicotine [Goldberg and Spealman. 1982]) depends critically upon the schedule of reinforcement. As we come to know more about the interaction of schedules of reinforcement with drugs as reinforcers it may become apparent that some drugs and schedules may be more effectively used than others in maintaining or Iimiting drug selfadministration in human and animal subjects. Such a generalization may also have application to the understanding of human individual differences in the reinforcing effects of drugs. 
4.6. Clarification of discrimlnative and reinforcing effects of drugs. Many investigators suggest that the discriminative effects of drugs in animals is predictive of the subjective effects of drugs in humans, including, "liking". This may, in turn, be related to the reinforcing effect of drugs (e.g., Schuster et al., 1981). There are few studies in animals and humans that have drawn such comparisons in the same experimental situation. Much will be gafned by a careful comparison of these stimulus characteristics in the future.

\section{Conclusions}

It should be clear that the proposition, viz., that the drugs that serve as reinforcers in animals are abused by humans, is greatly oversimplified. There are some exceptions that need further study. Further refinement will give the proposition more general predictability and usefulness. Nevertheless, the proposition has placed an appropriate focus upon the similarity of human and animal drug-taking that takes into account the critical nature of the process of reinforcement.

\section{Acknowledgements}

This paper was supported by USPHS Grant DA 00154 and DA 00254 . The manuscript was edited by G. Winger and typed by S. Baibak; both chores were done with care.

\section{References}

BALSTER, R.L., JOHANSON, C.E., HARRIS, R.T., and SCHUSTER, C.R. (1973) Phencyc11dine self-administration in the rhesus monkey. Pharmacol. Biochem. Behav., 1: 167-172. BIGELOW, G.E., GRIFFITHS, R.R., LIFBSON, I., and KALISZAK, J.E. (1980) Double-blind evaluation of reinforcing and anorectic actions of weight control medications: Interaction of pharmacological. and behavioral treatments. Arch. Gen. Psychiat., 37: 1118-1123.

CARNEY, J.M., UWAYDAH, I.M. and BALSTER, R.L. (1977) Evaluation of a suspension system for intravenous self-administration studies of water insoluble compounds in the rhesus monkey. Pharmacol. Blochem. Behav. 7: 357-364.

DENEAU, G. A. and INOKI, R. (1967) Nicotine self-admintstration in monkeys Ann. N.Y. Acad. Science 142: 277-279.

DENEAU, G. A., YANAGITA, T. and SEEVERS, M. H. (1969) Self-administration of psychoactive substances by the monkey: a measure of psychological dependence. Psychopharmacologia, 16: 30-48.

DEWTT, H., JOHANSON, C.E., UHLENHUTH, E.H., and MCCRACKEN, S. (1983) The effects of two non-pharmacological variables on drug preference in humans. In: Problems of Drug Dependence 1982, L.S. Harris (ed), pp 251-257, U.S. Government Printing office, Washington, D.C.

FORD, R.D. and BALSTER, R.L. (1977) Reinforcing properties of intravenous procaine in rhesus monkeys. Pharmaco1. Biochem. Behav. 6: 289-296.

GOLDBERG, S.R. and GARDNER, M.L. (1981) Second̄-order schedules: extended sequences of behavior controlled by brief environmental stimuli associated with drug selfadministration. In: Behavioral Pharmacology of Human Drug Dependence, T. Thompson and C.E. Johanson (eds.), pp 241-270 U.S. Government Printing office, Washington D.C.

GOLDBERG, S.R. and SPEALMAN, R.S. (1982) Maintenance and suppression of behavior by intravenous nicotine injection in squirrel monkeys. Fed. Proc. 41: 216-220.

GRIFFITH, J.D., CARRANZA, J, GRIFFITH, C, and MILIER, L. (1983) A comparison of bupropion and amphetamine for abuse 1lability. In: Problems of Drug Dependence 1982, L.S. Harris (ed.) PP 373. U.S. Government Printing Office, washington D.C.

GRIFFITHS, R.R., BIGELOW, G.E., LIEBSON, I., and KALISZAK, J.E. (1980) Drug preference in humans: double blind choice comparison of pentobarbital, diazepam, and placebo. J. Pharmacol. Exp. Ther. 215: 649-661.

GRIFFITHS, R.R., WINGER, G., BRADY, J.V. AND SNELL, J. D. (1976) Comparison of behavior maintained by infusions of eight phenylethylamines in baboons. Psychopharmacology 50: 251-258.

HOFFMEISTER, F. (1977) Assessment of reinforcing properties of stimulant and depressant 
drugs in the rhesus monkey as a tool for the prediction of psychic dependence-producing capability in man. In: Predicting Dependence Liability of Stimulant and Depressant Drugs, T. Thompson and K. R. Unna (eds.), pp 185-202. University Park Press, Baltimore.

HOFFMEISTER, F. (1979) Preclinical evaluation of reinforcing and adversive properties of analgesics. In: Mechanisms of Pain and Analgesjc Compounds, R.F. Beers and E.G. Bassett (eds.) pp 447-466. Raven Press, New York

HOFFMEISTER and GOLDBERG, S.R. (1973) A comparison of chlorpromazine, imipramine, morphine and d-amphetamine self-administration in cocaine-dependent rhesus monkeys. J. Pharmacol. Exp. Therap. 187: 8-14.

HOFFMEISTER, F. and WUTTKE, W. (1973) Negative reinforcting properties of morphIne antagonists in naive rhesus monkeys. Psychopharmacologia 33: 247-278.

JOHANSON, C.E. and UHLENHUTH, E.H. (1980) Drug preference and mood in humans: diazepam. Psychopharmacology 71: 269-275.

KROHN, D.D., BERTALMIO, A.J., WINGER, G., ard WOODS, J.H. (1982) Discriminative and relnforcing effects of tripelennamine alone and in combination with oplates in the rhesus monkey. Pharmacologist, 23: 230 .

LESTER, D. (1966) Self-selection of alcohol by animals, human variation and etiology of alcoholism. Quart. J. Stud. Alcohol 27: 395-438.

LUKAS, S.E. and GRIFFITHS, R.R. (1982) Comparfson of triazolam and diazepam self-administration by the baboon. Pharmacologist, 24: 133 .

MEISCH, R.A. and CARROLL, M.E. (1981) Establishment of orally delivered drugs as reinforcers for rhesus monkeys: Some relations to human drug dependence. In: Behavioral Pharmacology of Human Drug Dependence, T. Thompson and C.E. Johanson, (eds.) pp 197-209, U. S. Government Printing Office, Washington, D.C.

MELLO, N. K. and MENDELSON, J. H. (1965) Operant analysis of drinking patterns of chronic alcoholics. Nature 206: 43-46.

SCHUSTER, C.R., FISCHMAN, M.W. and JOHANSON, C.E. (1981) Internal stimulus control and subjective effects of drugs. In: Behavioral Pharmacology of Human Drug Dependence, T. Thompson and C.E. Johanson (eds.) pp 116-129, U.S. Government Printing office, Washington D.C.

TESSEL, R.E. and wOODS, J.H. (1978) Meta-substituted n-ethylamphetamine se1f-injection responding in the rhesus monkey: structure-activity relationships. J. Pharmacol. Exp. Ther. 205: 274-281.

THOMPSON, T. and SCHUSTER, C. R. (1964) Morphine self-administration and food reinforced and avoldance behavior in rhesus monkeys. Psychopharmacologia 5: 87-94.

WEEKS, J. R. (1962) Experimental morphine addiction: method for automatic intravenous infections in unrestrained rats. Science, 138: 143-144.

WIKLER, A. (1952) A psychodynamic study of a patient during experimental self-regulated re-addiction to morphine. Psychiat. Quart. 26: 270-293.

WILSON, M. C., HITOMI, M, and SCHUSTER, C.R. (1971) Psychomotor stimulant self-administration as a function of dosage per injection in the rhesus monkey. Psychopharmacologia 22: 271-281.

WINGER, G., BERTALMIO, A, and WOODS, J. H. (1983) Discriminative and reinforcing properties of the normetabolites of propoxyphene and meperidine In: Drug Discrimination: Applications in CNS Pharmacology, F.E. Colpaert and J.L. Slangen (eds.), pp 123-134, Elsevier Biomedical Press, Amsterdam.

WOOD, R.W., GRUBMAN, J. and WEISS, B. (1977) Nitrous oxide self-administration by the squirrel monkey. J. Pharmacol. Exp. Ther. 202: 491-499.

WOODS, J.H. (1978) The maintenance of drug self-injection responding by putative dopamine agonists in rhesus monkeys. Seventh International Congress of Pharmacology, Paris, France.

WOODS, J.H. (1982) Benzodlazepine dependence studies in animals: an overview. Drug Develop. Res. Supp. 1: 77-81.

WOODS, J.H., KATZ, J.L., MEDZIHRADSKY, F, SMITH, C.B. and WINGER, G.D. (1983) Evaluation of new compounds for opiold activity: 1982 annual report. In: Problems of Drug Dependence 1982, L.S. Harris (ed.), pp 457-511. U.S. Government Printing Office, Washington D.C.

WOODS, J. H., SMITH, C. B., MEDZIHRADSKY, F. and SWAIN, H. H. (1979) Preclinical testing of new analgesic drugs. In: Mechanisms of Pain and Analgesic Compounds, R.F. Beers and E.G. Bassett (eds.) pp 429-446 Raven Press, New York

WOODS, J.H. and TESSEL, R.E. (1974) Fenfluramine: amphetamine congener which fails to maintain drug-taking behavior in the rhesus monkey. Science, 185: 1067-1069. 
WOODS, J. H., YOUNG, A. M. and HERLING, S. (1982) Classification of narcotics on the basis of thejr reinforcing, discriminative and antagonist effects in rhesus monkeys. Fed. Proc. 41: 221-227.

WOODS, J. H., YOUNG, A. M., MEDZIHRADSKY, F., SMITH, C. B., ACETO, M. D., HARRIS, L. S. and JACOBSON A. E. (1983) Zomepirac: preclinical narcotic abuse liability evaluation. Arzne1m. Forsch./Drug Res. 33: 218-222.

YANAGITA, T. (1981) Dependence-producing effects of anxiolytics. In: Psychotropic Agents Part II: Anxiolytics Gerontopsychopharmacological Agents, and Psychmotor Stimulants, F. Hoffmeister and G. Stille (eds.) pp 395-405, Springer-Verlag, New York.

YANAGITA, T. TAKAHASHI, S., ISHIDA, K. and FUNAMOTO, H. (1970) Voluntary Inhalation of volatile anesthetics and organic solvents by monkeys. Jap. J. Clin. Pharmacol. 1: 13-16.

YOUNG, A. M. STEPHENS, R.R., HEIN, D.W. and WOODS, J.H. Reinforcing and discriminative stimulus properties of mixed agonist-antagonist opioids in monkeys. J. Pharmacol. Exp. Ther. (In press)

YOUNG, A. M., SWAIN, H. H. and WOODS, J. H. (1981) Comparison of opioid agonists in maintaining responding and in suppressing morphine withdrawal

in the rhesus monkey. Psychopharmacology 74: 329-335.

YOUNG, A.M. and WOODS, J.H. (1981) Maintenance of behavior by ketamine and related compounds in rhesus monkeys with different self-administration histories. J. Pharmacol. Exp. Ther. 218: 720-727.

Inquiries and reprint requests should be addressed to:

Dr. James H. Woods

Department of Pharmacology

M6322 Medical Sclence Bldg. I

University of Michigan Medical School

Ann Arbor, Michigan 48109 